\title{
Observed and modelled ecosystem respiration and gross primary production of a grassland in southwestern France
}

\author{
C. Albergel, J.-C. Calvet, A.-L. Gibelin, S. Lafont, J.-L. Roujean, C. Berne, O. Traullé, and N. Fritz \\ CNRM/GAME, Météo-France, CNRS, URA 1357, 42 avenue Coriolis, 31057 Toulouse Cedex 1, France
}

Received: 11 September 2009 - Published in Biogeosciences Discuss.: 19 January 2010

Revised: 28 April 2010 - Accepted: 2 May 2010 - Published: 21 May 2010

\begin{abstract}
In this work, the rich dataset acquired at the SMOSREX experimental site is used to enhance the A-gs version of the Interactions between Soil, Biosphere and Atmosphere (ISBA) model. A simple representation of the soil moisture effect on the ecosystem respiration is implemented in the ISBA-A-gs model. It results in an improvement of the modelled $\mathrm{CO}_{2}$ flux over a grassland in southwestern France. The former temperature-only dependent respiration formulation used in ISBA-A-gs is not able to model the limitation of the respiration under dry conditions. In addition to soil moisture and soil temperature, the only parameter required in this formulation is the ecosystem respiration parameter $\mathrm{Re}_{25}$. It can be estimated by means of eddy covariance measurements of turbulent nighttime $\mathrm{CO}_{2}$ flux (i.e. ecosystem respiration). The resulting correlation between observed and modelled net ecosystem exchange is $r^{2}=0.63$ with a bias of $-2.18 \mu \mathrm{mol} \mathrm{m}{ }^{-2} \mathrm{~s}^{-1}$. It is shown that when $\mathrm{CO}_{2}$ observations are not available, it is possible to use a more complex model, able to represent the heterotrophic respiration and all the components of the autotrophic respiration, to estimate $\mathrm{Re}_{25}$ with similar results. The modelled ecosystem respiration estimates are provided by the Carbon Cycle (CC) version of ISBA (ISBA-CC). ISBA-CC is a version of ISBA able to simulate all the respiration components, whereas ISBA-A-gs uses a single equation for ecosystem respiration. ISBA-A-gs is easier to handle and more convenient than ISBA-CC for the practical use in atmospheric or
\end{abstract}

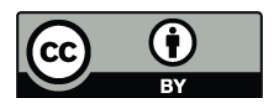

Correspondence to: J.-C. Calvet (calvet@meteo.fr) hydrological models. Surface water and energy flux observations, as well as Gross Primary Production (GPP) estimates, are compared with model outputs. The dependence of GPP to air temperature is investigated. The observed GPP is less sensitive to temperature than the modelled GPP. Finally, the simulations of the ISBA-A-gs model are analysed over a seven year period (2001-2007). Modelled soil moisture and Leaf Area Index (LAI) are confronted with the observed surface and root-zone soil moisture content $\left(\mathrm{m}^{3} \mathrm{~m}^{-3}\right)$, and with LAI estimates derived from surface reflectance measurements.

\section{Introduction}

A major component of the global carbon balance is the flux of $\mathrm{CO}_{2}$ from the soil, also referred to as soil respiration (Raich et al., 2002; Schlesinger et al., 2000). It is a major source of $\mathrm{CO}_{2}$ entering the atmosphere (20-40\% of the total flux, Kicklighter et al., 1994). The soil respiration represents 50 to $80 \%$ of the ecosystem respiration, $R_{\text {eco }}$ (Janssens et al., 2001; Epron et al., 1999). The soil respiration originates from the decomposition of the soil's organic matter (heterotrophic respiration) and from the roots (autotrophic respiration). Soil temperature and soil moisture are the two main factors controlling the rate at which $\mathrm{CO}_{2}$ is produced in the soil (Singh et al., 1977). The other component of $R_{\text {eco }}$, is the autotrophic respiration produced by the aboveground biomass. Various models have been proposed to describe soil respiration and $R_{\text {eco }}$. Generally, they are based on temperature-dependent relations (Katterer et al., 1998; Kirschbaum et al., 1995; Lloyd and Taylor, 1994) combined

Published by Copernicus Publications on behalf of the European Geosciences Union. 
with soil-water content estimates (Epron et al., 1999; Joffre et al., 2003).

The ISBA-A-gs (Calvet et al., 1998; Calvet and Soussana, 2001; Gibelin et al., 2006) version of the Interactions between Soil, Biosphere and Atmosphere (ISBA) model (Noilhan and Planton, 1988; Noilhan and Mahfouf, 1996), is able to simulate the Net Ecosystem Exchange (NEE) of $\mathrm{CO}_{2}$, together with plant growth (A-gs stands for net assimilation of $\mathrm{CO}_{2}$ and stomatal conductance). In ISBA-A-gs, a single equation is used to describe $R_{\text {eco }}$ (Rivalland et al., 2005). No distinction is made between autotrophic and heterotrophic respiration. The use of a unique term is justified by its simplicity and its robustness. However, the function used in ISBA-A-gs so far is temperature dependent only, whereas soil moisture constitutes, after temperature, the second factor regulating the soil $\mathrm{CO}_{2}$ efflux by limiting the respiration under dry conditions (Holt et al., 1990). The parameterisations can be compared and verified with nighttime turbulent eddy covariance measurements (Goulden et al., 1996; Aubinet et al., 2000).

A new Carbon Cycle (CC) version of ISBA, ISBA-CC, was developed by Gibelin et al. (2008) to represent the carbon fluxes and storage terms of the terrestrial carbon cycle. ISBA-CC is able to simulate above-ground and belowground biomass reservoirs. In a previous study (Gibelin et al., 2008), the simulated energy fluxes (sensible and latent heat) and net ecosystem exchange were validated against in situ measurements at 26 sites of the FLUXNET network (Baldocchi et al., 2001) with satisfactory results. ISBA-CC requires spin-up simulations to initialize the biomass reservoirs and the different carbon pools simulated by the model, and to reach the equilibrium for all of them. This model can be used for climatology purposes, to analyse retroactions between the climate and the carbon cycle, or to study future climate change scenarios. A more tractable and convenient model, like ISBA-A-gs, is required for other land surface modelling applications.

In this study, a new formulation of the ISBA-A-gs ecosystem respiration term is proposed; consisting of implementing soil-water content information following Joffre et al. (2003). The rich dataset of water, carbon and energy fluxes observed over the Surface Monitoring Of the Soil Reservoir EXperiment (SMOSREX) grassland site (De Rosnay et al., 2006) permits the testing of this formulation. Located at the ONERA (Office National d'Etudes et de Recherches Aérospatiales) site of Fauga-Mauzac, near Toulouse, in southwestern France, the SMOSREX long-term experiment aims at (1) improving the modelling of the microwave Lband emission of the soil-vegetation system and the understanding of soil-plant-atmosphere interactions, and (2) assess new land data assimilation systems aiming at enhancing the simulation of the surface fluxes (Albergel et al., 2010). The $\mathrm{CO}_{2}$ flux observations performed at the SMOSREX site are used to calibrate this formulation for a grassland. As $\mathrm{CO}_{2}$ flux observations are not available for all the biomes, the possibility to calibrate the ISBA-A-gs ecosystem respiration parameterisation from ISBA-CC simulations is investigated. Energy fluxes like latent and sensible heat fluxes are observed at SMOSREX and are compared with the simulated fluxes. As ISBA-A-gs can diagnose photosynthesis, or Gross Primary Production (GPP), this variable is compared with GPP estimates derived from the observations. In particular, the GPP response to air temperature is investigated. Finally, $R_{\text {eco }}$, GPP and the net $\mathrm{CO}_{2}$ flux or Net Ecosystem Exchange (NEE) are simulated for a seven year (2001-2007) period for the grassland of the SMOSREX site. Soil moisture and LAI are simulated as well and compared with observations.

\section{Materials and methods}

\subsection{Land surface model}

ISBA is a land surface model developed at Météo-France and implemented in atmospheric weather forecast models, hydrological models and global climate models (Noilhan and Mahfouf, 1996). In the ISBA version used in this study, the soil-water balance and the surface-energy balance are solved at 5-min time steps. The soil is represented by one bulk reservoir corresponding to the maximum rooting depth, including a thin surface layer and, regardless of the actual root development, according to Deardorff (1978). Mahfouf and Noilhan (1996) have introduced a drainage below the root-zone. The various soil-water and heat coefficients depend on soil texture. Surface temperature, soil moisture in the root-zone, surface soil moisture and the water and energy fluxes are the main surface variables simulated by ISBA. While only one energy balance equation is solved, a separation of soil evaporation and plant transpiration is done on the basis of the vegetation coverage. Radiation, temperature, air vapour pressure deficit and soil moisture allow the defining of the stomatal conductance. Different surface variables and parameters are required as input to ISBA, such as the surface albedo, LAI and vegetation height, as well as the soil texture, wilting point and field capacity.

\subsubsection{ISBA-A-gs and ISBA-CC}

On the basis of ISBA, Calvet et al. (1998) developed ISBAA-gs. It is a $\mathrm{CO}_{2}$ responsive version of ISBA which accounts for the effect of the atmospheric $\mathrm{CO}_{2}$ concentration and for the interactions between all environmental factors on the stomatal aperture. In the A-gs version of ISBA, photosynthesis and its coupling with stomatal conductance at a leaf level is accounted for. The vegetation net assimilation is computed and used as an input to a simple growth submodel able to predict LAI. ISBA-A-gs is able to simulate GPP, NEE, LAI, the energy and mass fluxes such as sensible and latent heat fluxes and soil moisture. ISBA-A-gs was implemented in SURFEX (Martin et al., 2007; Le Moigne 
et al., 2009), the modelling platform of Météo-France. In this study, SURFEX is used "off-line", i.e. without coupling the land surface with an atmospheric model. The values of the main soil and vegetation parameters used in the ISBA-Ags simulations over the SMOSREX grassland site are presented in Table 1. They are derived from the simulation of Calvet (2000) for the Monitoring the Usable soil Reservoir EXperimentally (MUREX) test site and from Gibelin et al. (2006). For herbaceous vegetation, ISBA-A-gs is able to simulate the above-ground biomass. However, it does not represent the other carbon reservoirs in the roots and in the soil. ISBA-CC was developed in order to have a more detailed representation of the carbon fluxes and of carbon storage (Gibelin et al., 2008). ISBA-CC and ISBA-A-gs share the same photosynthesis and leaf biomass growth submodels. In ISBA-CC, the carbon allocation and respiration terms are more detailed, by considering six biomass reservoirs. Following Parton et al. (1987), a heterotrophic respiration module accounts for five soil organic matter pools. The autotrophic and heterotrophic respiration modelling is described in detail in Gibelin et al. (2008).

In this study, several simulations of ISBA-CC and ISBAA-gs over the SMOSREX site are analysed for a seven year period (2001-2007).

\subsubsection{Modelling the ecosystem respiration with ISBA-A-gS}

In ISBA-A-gs, $R_{\text {eco }}$ is modelled by a temperature-dependent relation, a well-known $Q_{10}$ function, expressed by Eq. (1) (Rivalland et al., 2005).

$R_{\mathrm{eco}}=\operatorname{Re}_{25} \times Q_{10}^{\left(\frac{T_{2}-25}{10}\right)}$

where $\mathrm{Re}_{25}$ is the value of $R_{\mathrm{eco}}$ at $25^{\circ} \mathrm{C}, T_{2}$ is root-zone temperature and $Q_{10}$ is set to 2 . Joffre et al. (2003), proposed to account for the soil moisture effect by introducing a scaling factor, $f\left(w_{\mathrm{g}}\right)$. The $f\left(w_{\mathrm{g}}\right)$ term is expressed as the ratio of soil moisture to field capacity $\left(w_{\mathrm{fc}}\right)$ :

$f\left(w_{\mathrm{g}}\right)=\frac{w_{\mathrm{g}}}{w_{\mathrm{fc}}}$

For values of $w_{\mathrm{g}}$ higher than $w_{\mathrm{fc}}, f\left(w_{\mathrm{g}}\right)$ is forced to 1 :

$f\left(w_{\mathrm{g}}\right)=$ min_value $\left(\frac{w_{\mathrm{g}}}{w_{\mathrm{fc}}}, 1\right)$

$R_{\text {eco }}$ is now expressed as:

$R_{\text {eco }}=\operatorname{Re}_{25} \times f\left(w_{\mathrm{g}}\right) \times Q_{10}^{\left(\frac{T_{2}-25}{10}\right)}$

From the NEE values observed at SMOSREX, together with the observed surface soil moisture $\left(w_{\mathrm{g}}, 0-6 \mathrm{~cm}\right)$ and soil temperature $\left(T_{2}, 20 \mathrm{~cm}\right)$, it is possible to calibrate the $\operatorname{Re}_{25}$ parameter of the $R_{\text {eco }}$ parameterization. The $\mathrm{Re}_{25}$ parameter, is best fitted by minimising the Root Mean Square Error (RMSE) between $R_{\text {eco }}$ estimates from Eq. (4) and nighttime NEE observations sorted according to
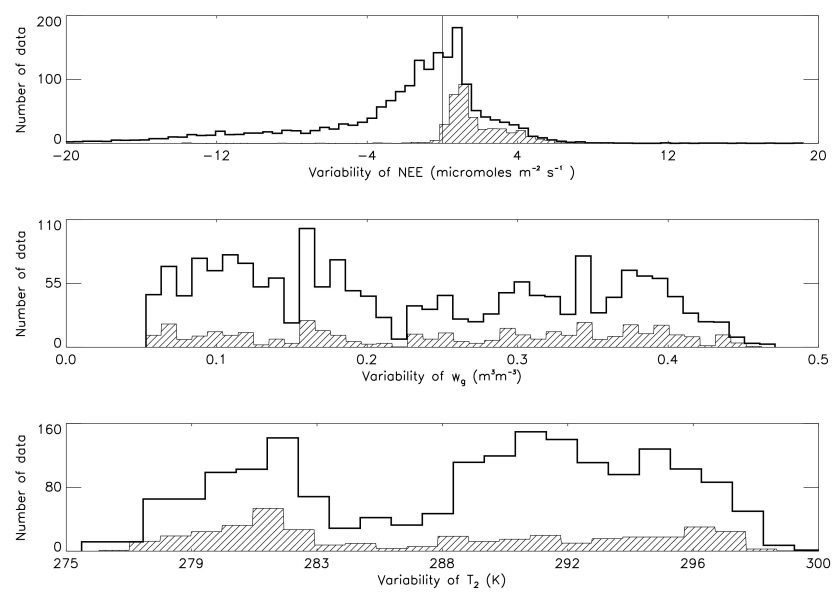

Fig. 1. Variability of the net $\mathrm{CO}_{2}$ flux, $w_{\mathrm{g}}$ and $T_{2}$ for wind direction between 225 and 315 degrees, sufficient turbulent exchange $\left(u^{*}>0.16 \mathrm{~ms}^{-1}\right)$, and in the absence of water deposition, for nighttime data only (dashed area) and for pooled daytime and nighttime data (thick line).

- the dominant wind direction at the SMOSREX site (in order to ensure a sufficient fetch, the flux station was installed at the eastern edge of the grassland field, i.e. downstream of the dominant westerly winds, therefore, the flux values are used for wind direction between 225 and $315^{\circ}$, only),

- the absence of water deposition,

- a sufficient turbulent exchange rate for the application of the method (friction velocity, $u^{*}$, above a site-specific threshold).

It is necessary to verify that under these conditions, there is a sufficient variability of $w_{\mathrm{g}}$ and $T_{2}$. Figure 1 shows the probability density functions (pdf) of NEE, $w_{\mathrm{g}}$ and $T_{2}$, for (i) nighttime observations only, and (ii) pooled daytime and nighttime observations. For both $w_{\mathrm{g}}$ and $T_{2}$, the nighttime pdf is similar to the pdf for the whole dataset. The $w_{\mathrm{g}}$ values range from 0.05 to $0.50 \mathrm{~m}^{3} \mathrm{~m}^{-3}$ and $T_{2}$ ranges from 276 to $300 \mathrm{~K}$.

Also, Eq. (4) can be calibrated from ISBA-CC simulations of ecosystem respiration. Four different simulations were performed with ISBA-A-gs, one for each best-fit $\operatorname{Re}_{25}$ parameter, corresponding to either observed or modelled $R_{\text {eco }}$ and to either Eq. (1) or Eq. (4).

\subsection{The SMOSREX experimental site}

Part of the SMOSREX experimental site is covered by a grassland of about $3.2 \times 10^{4} \mathrm{~m}^{2}(180 \mathrm{~m} \times 180 \mathrm{~m})$, mown once a year at wintertime. In this study, half-hourly SMOSREX data are used, covering a 7-year period (2001-2007). At SMOSREX, all the atmospheric forcing variables required to run ISBA-A-gs or ISBA-CC are measured: atmospheric 
Table 1. Main soil and vegetation parameters used for the SMOSREX grassland in the ISBA-A-gs model.

\begin{tabular}{|c|c|c|c|}
\hline Parameter & Symbol & Unit & Value \\
\hline \multicolumn{4}{|c|}{ Soil Parameters } \\
\hline Soil depth & $d_{2}$ & $\mathrm{~m}$ & 0.95 \\
\hline Sand content & SAND & $\%$ & 32.0 \\
\hline Clay content & CLAY & $\%$ & 22.8 \\
\hline Field capacity & $w_{\mathrm{fc}}$ & $\mathrm{m}^{3} \mathrm{~m}^{-3}$ & 0.30 \\
\hline Wilting point & $w_{\text {wilt }}$ & $\mathrm{m}^{3} \mathrm{~m}^{-3}$ & 0.17 \\
\hline \multicolumn{4}{|c|}{ Vegetation parameters } \\
\hline $\begin{array}{l}\text { Mesophyll conductance in } \\
\text { well-watered condition }\end{array}$ & $g_{\mathrm{m}} *$ & $\mathrm{mms}^{-1}$ & 1 \\
\hline $\begin{array}{l}\text { Critical extractable soil } \\
\text { moisture content }\end{array}$ & $\theta_{\mathrm{c}}$ & Dimensionless & 0.3 \\
\hline $\begin{array}{l}\text { Soil moisture stress } \\
\text { response strategy }\end{array}$ & - & - & Drought-tolerant \\
\hline Maximum leaf span time & $\tau_{\mathrm{M}}$ & Days & 150 \\
\hline Minimum leaf area index & $\mathrm{LAI}_{\min }$ & $\mathrm{m}^{2} \mathrm{~m}^{-2}$ & 0.3 \\
\hline Cuticular conductance & $g_{\mathrm{c}}$ & $\mathrm{mm} \mathrm{s}^{-1}$ & 0.25 \\
\hline $\begin{array}{l}\text { SLA (specific leaf area) } \\
\text { sensitivity to } N_{\mathrm{L}} \text { (leaf } \\
\text { nitrogen concentration) }\end{array}$ & $e$ & $\mathrm{~m}^{2} \mathrm{~kg}^{-1}$ & 5.56 \\
\hline SLA at $N_{\mathrm{L}}=0$ & $f$ & $\mathrm{~m}^{2} \mathrm{~kg}^{-1}$ & 6.73 \\
\hline $\begin{array}{l}\text { Ecosystem respiration } \\
\text { at } 25^{\circ} \mathrm{C}\end{array}$ & $\operatorname{Re}_{25}$ & $\mu \mathrm{mol} \mathrm{m} \mathrm{s}^{2} \mathrm{~s}^{-1}$ & $\begin{array}{l}\text { Calibrated from } \\
\text { observed/modelled } \\
\text { data }\end{array}$ \\
\hline $\begin{array}{l}\text { Leaf nitrogen } \\
\text { concentration }\end{array}$ & $N_{\mathrm{L}}$ & $\%$ of dry mass & 1.3 \\
\hline
\end{tabular}

pressure, air humidity, air temperature, long-wave and shortwave incident radiation, rain rate, wind speed. Soil moisture is observed at ten depths, 0-6, 10, 20, 30, 40, 50, 60, 70, 80, $90 \mathrm{~cm}$ with an half-hourly time step. From those measurements it is possible to estimate the root-zone soil moisture content $w_{2}\left(\mathrm{~m}^{3} \mathrm{~m}^{-3}\right)$, integrated over the root-zone profile $(0-95 \mathrm{~cm})$. Temperatures are observed at different depths in the soil, 1, 5, 20, 50, $90 \mathrm{~cm}$, and at $2 \mathrm{~m}$ above the ground. Also, surface temperature is measured using a Heitronics infrared thermometer. Surface shortwave reflectances are determined thanks to two CIMEL radiancemeters.

\subsection{1 $\mathrm{CO}_{2}$ flux measurements and GPP estimations}

At the SMOSREX site, the $\mathrm{CO}_{2}$ flux measurements are done through the eddy covariance micrometeorological method (Moncrieff et al., 1997; Aubinet et al., 2000; Foken, 2008). The wind speed components are measured at $3.5 \mathrm{~m}$ above the ground with an Ultrasonic 3-D anemometer (GILL Instruments, Horizontal Research 1199 HS, 50 Hz). Water vapour and carbon dioxide concentrations are measured with an open-path IRGA (Infra Red Gas Analyser) analyser (LiCor, LI-7500, 20 Hz). Eddy covariance measurements of the $\mathrm{CO}_{2}$ efflux are processes on a half-hourly basis and are available for the period from May 2005 to December 2007.

The open-path LI-7500 sensor can be affected by water deposition through rainfall or dew. Indeed, the open-path technique is more subjected to the influence of meteorological conditions like rain or dew than the close-path technique. Heusinkveld et al. (2008) showed that the presence of dew on the optical windows of an open-path IRGA analyser greatly decreases the data quality. The contaminated observations were detected and filtered out using in situ water deposition observations (Wetness sensing grids 237, Campbell Scientific Ltd). Water deposition affects about $39 \%$ of the flux measurements already filtered for wind direction. The distribution of the filtered $\mathrm{CO}_{2}$ flux observations is presented in Fig. 1 (top).

From these measurements, $R_{\text {eco }}$ could be estimated at nighttime under specific conditions. Indeed, the lack of turbulence may affect the observation of the NEE (Goulden et al., 1996). Under a friction velocity threshold, in calm and stable nighttime conditions, $\mathrm{CO}_{2}$ storage may occur in the air layer below the eddy flux system. Hence, measurements under those conditions are not considered. The $u^{*}$ threshold is site-specific and the value $u^{*}>0.16 \mathrm{~m} \mathrm{~s}^{-1}$ was found to give the best scores (Table 2). From the nighttime $\mathrm{CO}_{2}$ flux data, it is possible to calibrate the $R_{\text {eco }}$ function of ISBA-Ags. From the latter, an estimation of the observed half-hourly GPP can be obtained: first, $R_{\text {eco }}$ is derived from Eq. (4), with the observed soil moisture and temperature values; second, $R_{\text {eco }}$ is removed from the half-hourly NEE observations, in order to estimate the amount of $\mathrm{CO}_{2}$ that is fixed by the plant through photosynthesis, i.e. the GPP.

\subsubsection{Water and energy flux measurements}

Net Radiation $(\mathrm{Rn})$ has been measured at SMOSREX since 2001 with a half-hourly time step. Sensible Heat $(\mathrm{H})$ and latent heat (LE) fluxes have been measured since 2005, and for $\mathrm{H}$, two methods are used. In addition to the eddy covariance method, sensible heat is measured by the aerodynamic method as well. The former is based on the device used for the MUREX experimental site (Calvet et al., 1999). As for NEE, LE and $\mathrm{H}$ fluxes derived from the eddy covariance method have to be filtered for wind direction and water deposition.

\subsubsection{Surface reflectance measurements}

Incoming solar radiation at several wavelengths and the upward luminance reflected by the surface at a $40^{\circ}$ incidence angle are measured over the grassland thanks to two CIMEL radiancemeters. From those measurements, it is possible to determine the surface reflectance at five wavelengths, from the visible to the shortwave infrared (blue: $430-470 \mathrm{~nm}$, green: $506.5-591.5 \mathrm{~nm}$, red: $621.5-674.5 \mathrm{~nm}$, near infrared: 792-883 $\mathrm{nm}$ and shortwave infrared: $1557.7-1722.5 \mathrm{~nm})$. A method developed by Roujean and Lacaze (2002) permits the production of LAI, from the surface reflectances. Destructive observations of the vegetation characteristics (LAI, green and brown biomass) were performed from 2001 to 2006 as well. 
Table 2. Calibration of $\mathrm{Re}_{25}$ from (left) nighttime observations of NEE (i.e. ecosystem respiration), filtered by wind direction, $u^{*}$ above $0.16 \mathrm{~ms}^{-1}$, and the absence of water deposition and (right) using the ecosystem respiration simulated by the ISBA-CC model. The calibration is performed by minimising the RMSE between either Eq. (4) or Eq. (1) and the observations or the ISBA-CC simulations.

\begin{tabular}{ccrcccc}
\hline $\begin{array}{c}R_{\text {eco }} \\
\text { parameterisation }\end{array}$ & \multicolumn{3}{c}{ Calibrated from observations } & \multicolumn{3}{c}{ Calibrated from ISBA-CC simulations } \\
& $\begin{array}{c}\text { RMSE } \\
\left(\mu \mathrm{mol} \mathrm{m}^{-2} \mathrm{~s}^{-1}\right)\end{array}$ & $\begin{array}{r}\text { Bias } \\
\left(\mu \mathrm{mol} \mathrm{m}^{-2} \mathrm{~s}^{-1}\right)\end{array}$ & $\begin{array}{c}\mathrm{Re}_{25} \\
\left(\mu \mathrm{mol} \mathrm{m}^{-2} \mathrm{~s}^{-1}\right)\end{array}$ & $\begin{array}{c}\text { RMSE } \\
\left(\mu \mathrm{mol} \mathrm{m}^{-2} \mathrm{~s}^{-1}\right)\end{array}$ & $\begin{array}{c}{ }^{2}\left(\mu \mathrm{mol}_{2} \mathrm{~m}^{-2} \mathrm{~s}^{-1}\right) \\
\left(\mu \mathrm{mol} \mathrm{m}^{-2} \mathrm{~s}^{-1}\right)\end{array}$ \\
\hline Eq. (4) & 1.36 & 0.13 & 5.22 & 0.71 & -0.05 & 5.00 \\
Eq. (1) & 1.63 & -0.07 & 3.63 & 0.86 & -0.17 & 3.18 \\
\hline
\end{tabular}

\subsection{Comparison between observed and simulated variables}

The modelled $\mathrm{CO}_{2}$ fluxes are compared with two groups of observations: (1) sorted by wind direction (between 225 and 315 degrees) and sufficient turbulent exchange $\left(u^{*}>0.16 \mathrm{~m} \mathrm{~s}^{-1}\right.$, see Sect. 2.2.1), and (2) sorted by wind direction, sufficient turbulent exchange and the absence of water deposition. The observed eddy correlation fluxes are averaged over a 30-min period. Although the model time step for solving the land-atmosphere exchange processes is 5-min, the model simulations are analysed using 30-min intervals. For each group of observations, model scores are calculated: squared correlation coefficient $\left(r^{2}\right)$, the Root Mean Square Error (RMSE) and the bias (observed data minus modelled data). The RMSE is used to set the $\operatorname{Re}_{25}$ parameter in Eqs. (1) and (4).

\section{Results}

\subsection{Investigating NEE, $R_{\text {eco }}$ and GPP}

The $\operatorname{Re}_{25}$ values of Eqs. (4) and (1) were set to $5.22 \mu \mathrm{mol} \mathrm{m}{ }^{-2} \mathrm{~s}^{-1}$ and $3.63 \mu \mathrm{mol} \mathrm{m}^{-2} \mathrm{~s}^{-1}$, respectively, by minimising the RMSE between the ecosystem respiration derived from Eqs. (4) and (1) and the observed filtered values of $\mathrm{CO}_{2}$ measurements (see above). Another calibration of Eqs. (4) and (1) was done with $R_{\text {eco }}$ modelled by ISBA-CC, and gave similar results: $\mathrm{Re}_{25}$ best-fit values of $5.00 \mu \mathrm{mol} \mathrm{m}^{-2} \mathrm{~s}^{-1}$ for Eq. (4) and $3.18 \mu \mathrm{mol} \mathrm{m}^{-2} \mathrm{~s}^{-1}$ for Eq. (1). The calibration results are summarised in Table 2.

Figure 2 presents monthly NEE simulations by ISBA-Ags, based on $R_{\text {eco }}$ calculations from either Eq. (1) or Eq. (4). Table 3 presents a comparison of the half-hourly NEE simulated by ISBA-A-gs with the two groups of observations described in Sect. 2.3.

- For the first group (unfiltered for water deposition), using either Eqs. (1) and (4) leads to rather poor scores: $r^{2}=0.43$ for both equations, RMSE $=4.45$ and $4.33 \mu \mathrm{mol} \mathrm{m}^{-2} \mathrm{~s}^{-1}$, bias $=-2.46$ and $-2.21 \mu \mathrm{mol} \mathrm{m}^{-2} \mathrm{~s}^{-1}$ for Eqs. (1) and (4),

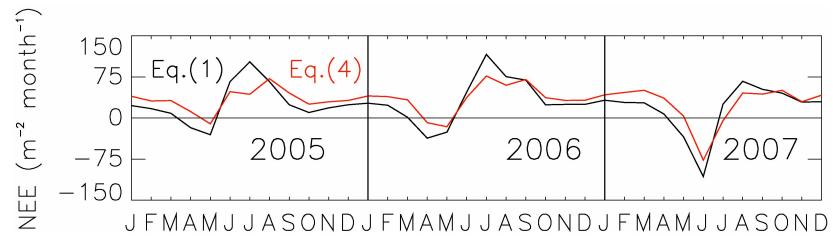

Fig. 2. Monthly NEE (sum of the net $\mathrm{CO}_{2}$ flux) simulated by ISBAA-gs using $R_{\text {eco }}$ calculated from either Eq. (1) or Eq. (4) (black and red line, respectively).

respectively. Using Eq. (4) with $\mathrm{Re}_{25}$ calibrated from the ISBA-CC ecosystem respiration gives similar results: $r^{2}=0.44$, RMSE $=4.29 \mu \mathrm{mol} \mathrm{m}^{-2} \mathrm{~s}^{-1}$ and bias $=-2.10 \mu \mathrm{mol} \mathrm{m} \mathrm{m}^{-2} \mathrm{~s}^{-1}$.

- For the second group (filtered for water deposition), better scores are obtained: $r^{2}=0.58$ and 0.63 , RMSE $=4.13$ and $3.87 \mu \mathrm{mol} \mathrm{m}^{-2} \mathrm{~s}^{-1}$, bias $=-2.61$ and $-2.18 \mu \mathrm{mol} \mathrm{m}^{-2} \mathrm{~s}^{-1}$, for Eqs. (1) and (4), respectively. Using Eq. (4) with $\mathrm{Re}_{25}$ calibrated from the ISBA-CC ecosystem respiration gives similar results, with $r^{2}=0.63$, RMSE $=3.81 \mu \mathrm{mol} \mathrm{m}^{-2} \mathrm{~s}^{-1}$ and bias $=-2.07 \mu \mathrm{mol} \mathrm{m}{ }^{-2} \mathrm{~s}^{-1}$.

Despite the low bias values found when calibrating the ecosystem respiration parameter (see Table 2), the bias between the half-hourly NEE simulated by ISBA-A-gs and the observations is high. Indeed, the ecosystem respiration parameter is calibrated using nighttime data and Table 3 considers pooled daytime and nighttime data. On the basis of the results obtained with and without water deposition filtering, it can be argued that combining water deposition measurements with eddy covariance measurements is of interest. Excluding water deposition periods permits the elimination of noisy open-path IRGA eddy covariance observations. Indeed, the nocturnal $R_{\text {eco }}$ observations are much more scattered in water deposition conditions than for a dry surface (standard deviation values of $3.24 \mu \mathrm{mol} \mathrm{m}^{-2} \mathrm{~s}^{-1}$, and $1.71 \mu \mathrm{mol} \mathrm{m}^{-2} \mathrm{~s}^{-1}$, respectively). The filtering process might also exclude incorrect simulations of $R_{\text {eco }}$ caused by the difficulty to model respiration with the simple Eq. (4), especially in wet conditions (anaerobic limitation of soil 
Table 3. Comparison between observed and modelled (ISBA-A-gs) NEE using either Eq. (1) or Eq. (4). The modelled NEE is compared with NEE observations, with and without filtering for water deposition.

\begin{tabular}{|c|c|c|c|c|c|c|c|}
\hline \multirow[t]{2}{*}{$\begin{array}{l}\text { Parameterization } \\
\text { used for } R_{\text {eco }} \\
\text { in ISBA-A-gs }\end{array}$} & \multirow[t]{2}{*}{$\begin{array}{l}\text { Reference } \\
\text { used for the } \\
\text { calibration } \\
\text { of } \operatorname{Re}_{25}\end{array}$} & \multicolumn{3}{|c|}{$\begin{array}{l}\text { Observed pooled daytime and } \\
\text { nighttime } \mathrm{CO}_{2} \text { flux filtered for } \\
\text { wind direction, and } \\
u^{*}>0.16 \mathrm{~ms}^{-1}\end{array}$} & \multicolumn{3}{|c|}{$\begin{array}{c}\text { Observed pooled daytime and } \\
\text { nighttime } \mathrm{CO}_{2} \text { flux filtered for } \\
\text { wind direction, } u^{*}>0.16 \mathrm{~ms}^{-1} \text {, } \\
\text { and the absence of water } \\
\text { deposition }\end{array}$} \\
\hline & & $r^{2}$ & $\begin{array}{c}\text { RMSE } \\
\left(\mu \mathrm{mol} \mathrm{m}{ }^{2} \mathrm{~s}^{-1}\right)\end{array}$ & $\begin{array}{c}\text { Bias } \\
\left(\mu \mathrm{mol} \mathrm{m}{ }^{2} \mathrm{~s}^{-1}\right)\end{array}$ & $r^{2}$ & $\begin{array}{c}\text { RMSE } \\
\left(\mu \mathrm{mol} \mathrm{m}^{2} \mathrm{~s}^{-1}\right)\end{array}$ & $\begin{array}{c}\text { Bias } \\
\left(\mu \mathrm{mol} \mathrm{m}^{2} \mathrm{~s}^{-1}\right)\end{array}$ \\
\hline $\begin{array}{l}\text { Eq. (1) } \\
\operatorname{Re}_{25}=3.63 \\
\left(\mu \mathrm{mol} \mathrm{m} \mathrm{m}^{-2} \mathrm{~s}^{-1}\right)\end{array}$ & $\begin{array}{l}\text { Nighttime } \\
\text { NEE } \\
\text { observations }\end{array}$ & 0.43 & 4.45 & -2.46 & 0.58 & 4.13 & -2.61 \\
\hline $\begin{array}{l}\text { Eq. (4) } \\
\operatorname{Re}_{25}=5.22 \\
\left(\mu \mathrm{mol} \mathrm{m}^{-2} \mathrm{~s}^{-1}\right)\end{array}$ & $\begin{array}{l}\text { Nighttime } \\
\text { NEE } \\
\text { observations }\end{array}$ & 0.43 & 4.33 & -2.21 & 0.63 & 3.87 & -2.18 \\
\hline $\begin{array}{l}\text { Eq. (4) } \\
\operatorname{Re}_{25}=5.22 \\
\left(\mu \mathrm{mol} \mathrm{m} \mathrm{m}^{-2} \mathrm{~s}^{-1}\right) \\
+ \text { prescribed LAI }\end{array}$ & $\begin{array}{l}\text { Nighttime } \\
\text { NEE } \\
\text { observations }\end{array}$ & 0.47 & 4.10 & -2.04 & 0.66 & 3.48 & -1.92 \\
\hline $\begin{array}{l}\text { Eq. (4) } \\
\operatorname{Re}_{25}=5.00 \\
\left(\mu \mathrm{mol} \mathrm{m}^{-2} \mathrm{~s}^{-1}\right)\end{array}$ & $\begin{array}{l}\text { ISBA-CC } \\
\text { model }\end{array}$ & 0.44 & 4.29 & -2.10 & 0.63 & 3.81 & -2.07 \\
\hline
\end{tabular}
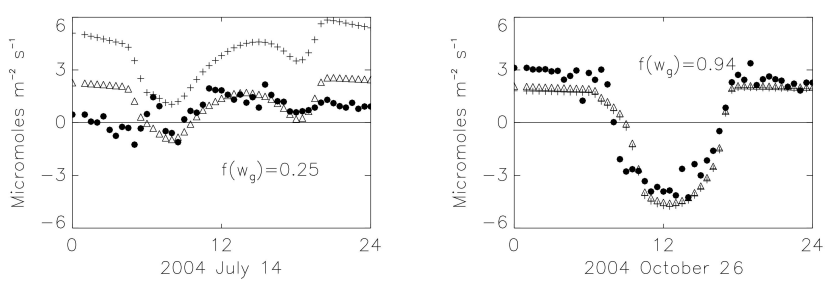

Fig. 3. Comparison of NEE simulations of ISBA-A-gs based on $R_{\text {eco }}$ calculated from either Eq. (1) or Eq. (4) (+ and triangles, respectively), with NEE observations (dots), for two days presenting contrasting soil moisture conditions: (left) 14 July 2004, (right) 26 October 2004 .

respiration above field capacity) and dry conditions (respiration pulses following the rewetting of the soil). However, separate analysis (not shown) has concluded that the distribution of the model difference with the observations during water deposition situations does not vary much from wet to dry soil moisture conditions. In the following, water-deposition free, turbulent condition and wind filtered data are only considered.

Seasonal statistical scores show that the impact of implementing $f\left(w_{\mathrm{g}}\right)$ varies from one season to another. At springtime (March, April, May), 1551 NEE half-hourly observations are available, including 1181 observations with $f\left(w_{\mathrm{g}}\right)$ equal to 1 (about 76\%). Consequently, the $r^{2}$ scores of NEE simulated with $R_{\text {eco }}$ estimates from either Eq. (1) or
Eq. (4) are similar: 0.79 and 0.81 , respectively. In summer (June, July, August), $f\left(w_{\mathrm{g}}\right)$ is rarely equal to 1 (27 times in 2608 observations, about $1 \%$, only), and the $r^{2}$ scores of NEE simulated with $R_{\text {eco }}$ estimates from either Eq. (1) or Eq. (4) are different: 0.41 and 0.56 , respectively.

Figure 3 shows the impact of using either Eq. (1) or Eq. (4) on the simulated NEE in contrasting soil moisture, soil temperature and LAI condition for two days under clear sky conditions. The measured $w_{\mathrm{g}}, T_{2}$ and LAI at 12:00 UTC, on 14 July and 26 October 2004 are: $0.14 \mathrm{~m}^{3} \mathrm{~m}^{-3}, 292.0 \mathrm{~K}$, $1.3 \mathrm{~m}^{2} \mathrm{~m}^{-2}$ and $0.35 \mathrm{~m}^{3} \mathrm{~m}^{-3}, 289.6 \mathrm{~K}, 0.6 \mathrm{~m}^{2} \mathrm{~m}^{-2}$, respectively. In dry conditions (14 July 2004, with a $f\left(w_{\mathrm{g}}\right)$ daily average of about 0.25), Eqs. (1) and (4) provide contrasting results and the NEE estimates using Eq. (4) are much closer to the observations. In wet conditions (26 October 2004, with a $f\left(w_{\mathrm{g}}\right)$ daily average of about 0.94$)$, there is less of a difference between the NEE estimates.

Finally, the temperature dependence of GPP was investigated using the observed infrared temperatures, from $\mathrm{Au}-$ gust 2003 to 2007. Figure 4 illustrates the evolution of the GPP modelled by ISBA-A-gs and the evolution of the GPP derived from the observations (see Sect. 2.2.1) as a function of the binned infrared temperature. The temperature classes correspond to 5\% percentile bins, from 0 to $95 \%$, and then above $99 \%$ ). For both modelled and observed GPP, the median value is presented together with 6 percentiles $(5,10,20$, 80,90 , and $95 \%$ ). An optimum temperature can be derived from peak GPP median values. For the modelled GPP, the 
Table 4. ISBA-A-gs and ISBA-CC scores for water and energy fluxes: Net Radiation (Rn), Latent Heat (LE) and sensible Heat $(\mathrm{H})$. For $\mathrm{H}$, eddy covariance and aerodynamic measurements are available. The observations are filtered for wind direction, $u^{*}>0.16 \mathrm{~ms}^{-1}$, and the absence of water deposition.

\begin{tabular}{lrrrrrr}
\hline & \multicolumn{3}{c}{ ISBA-A-gs } & \multicolumn{3}{c}{ ISBA-CC } \\
\cline { 2 - 7 } & $r^{2}$ & $\begin{array}{r}\text { Bias } \\
\left(\mathrm{Wm}^{-2}\right)\end{array}$ & $\begin{array}{r}\text { RMSE } \\
\left(\mathrm{Wm}^{-2}\right)\end{array}$ & $r^{2}$ & $\begin{array}{r}\text { Bias } \\
\left(\mathrm{Wm}^{-2}\right)\end{array}$ & $\begin{array}{r}\text { RMSE } \\
\left(\mathrm{Wm}^{-2}\right)\end{array}$ \\
\hline $\mathrm{Rn}$ & 0.98 & -9.7 & 27.6 & 0.97 & -9.0 & 28.5 \\
LE & 0.65 & -2.0 & 104.6 & 0.59 & -6.4 & 106.0 \\
eddy covariance & & 10.9 & 46.5 & 0.78 & 15.5 & 47.6 \\
$\begin{array}{l}\text { eddy covariance } \\
\text { eddy }\end{array}$ & 0.78 & 10.9 & & & & \\
$\begin{array}{l}\mathrm{H} \\
\text { aerodynamic }\end{array}$ & 0.41 & 8.3 & 58.9 & 0.42 & 10.8 & 60.6 \\
\hline
\end{tabular}
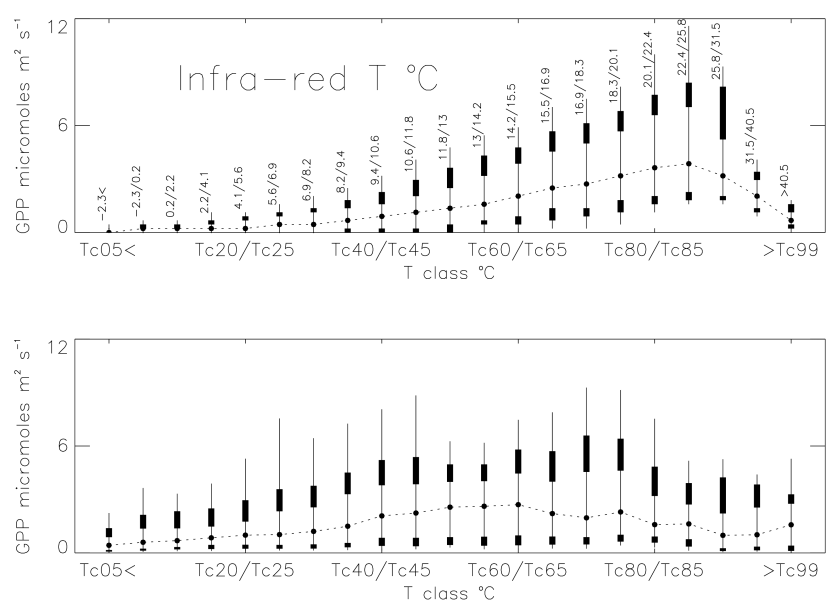

Fig. 4. Response of (top) the simulated GPP and of (bottom) the estimated GPP to the observed surface infrared-derived temperature. The median difference (dots) is presented together with percentile values. Line: 5-95\% percentile, closed box (bottom) 10$20 \%$ percentile, closed box (top) $80-90 \%$ percentile. GPP statistics are given for 21 temperature classes $\left(T_{\mathrm{c}}\right)$ corresponding to $5 \%$ percentile intervals.

peak median GPP is between classes 85 and $90 \%$ and corresponds to an average optimum temperature of about $24^{\circ} \mathrm{C}$. The use of the air temperature instead of the infrared temperature leads to a lower optimum temperature of about $20.5^{\circ} \mathrm{C}$ (not shown). On the other hand, the temperature response of the GPP, derived from the observations, is rather flat and it is difficult to identify an optimum temperature. The optimum median value of the observed GPP corresponds to average infrared and air temperatures of $14.8^{\circ} \mathrm{C}$ and $14.3^{\circ} \mathrm{C}$, respectively. These results tend to indicate that the temperature response, simulated by ISBA-A-gs for this grassland, is too strong and is likely to overestimate the optimal temperature.
Table 5. Carbon budget of the SMOSREX grassland derived from the ISBA-A-gs simulations from 2001 to 2007: yearly amounts of ecosystem respiration $\left(R_{\mathrm{eco}}\right)$ and Gross Primary Production (GPP).

\begin{tabular}{cccc}
\hline & \multicolumn{2}{c}{$R_{\text {eco }}$} & $\begin{array}{c}\text { GPP } \\
\text { (yearly amount } \mathrm{gC} \mathrm{m}^{-2} \text { ) }\end{array}$ \\
\cline { 2 - 4 } & Eq. (4) & Eq. (1) & \\
\hline 2001 & 731 & 717 & 750 \\
2002 & 753 & 698 & 575 \\
2003 & 761 & 869 & 392 \\
2004 & 743 & 757 & 549 \\
2005 & 712 & 769 & 435 \\
2006 & 744 & 830 & 437 \\
2007 & 697 & 731 & 505 \\
\hline
\end{tabular}

\subsection{Investigating $\mathrm{Rn}, \mathrm{LE}$ and $\mathrm{H}$}

The results are summarised in Table 4. The $r^{2}$ between the observed $\mathrm{Rn}$ and the simulated one is 0.98 , with a bias of about $-9.7 \mathrm{Wm}^{-2}$. Similar scores are found for ISBA-CC (0.97 and $-9.0 \mathrm{Wm}^{-2}$, respectively). Lower $r^{2}$ and bias values are obtained for LE: 0.65 and $-2.0 \mathrm{Wm}^{-2}$ for ISBAA-gs, and 0.59 and $-6.4 \mathrm{Wm}^{-2}$ for ISBA-CC, respectively. The sensible heat flux is measured with both aerodynamic and eddy covariance methods. The eddy covariance observations correlate better with the simulations, with $r^{2}=0.78$ for both ISBA-A-gs and ISBA-CC. In both cases, the bias is greater than $10 \mathrm{Wm}^{-2}$. The aerodynamic method presents smaller $r^{2}$ values: 0.41 and 0.42 for ISBA-A-gs and ISBA$\mathrm{CC}$, respectively. Biases are high as well.

Figure 5 shows the ability of the model to reproduce the diurnal cycle. It presents the energy and water fluxes measured using the eddy covariance method and modelled with ISBA-A-gs, for one day (under clear sky conditions) for each month from May to August 2007. Although the same seasonal trends are observed, rather large differences occur in the partitioning of energy between $\mathrm{H}$ and LE.

\subsection{A seven year modelling period with ISBA-A-gs}

Figure 6 presents cumulative curves of GPP, $R_{\text {eco }}$ and NEE for a seven-year (2001-2007) simulation performed by ISBA-A-gs for the SMOSREX grassland, using Eq. (4). The cumulative $R_{\text {eco }}$ curves show that accounting for soil moisture in Eq. (4) strongly reduces the interannual variability of $R_{\text {eco }}$. With Eq. (1), the curves tend to diverge from June onwards (not shown), in response to the large interannual variability of soil temperature at summertime. With Eq. (4), the various cumulative $R_{\text {eco }}$ curves are more similar.

The accumulated $R_{\text {eco }}$ and GPP are presented for each year in Table 5. For ecosystem respiration, results for both Eqs. (1) and (4) are presented. Whereas Eq. (4) reduces $R_{\text {eco }}$ at summertime when drought limits respiration, the yearly 

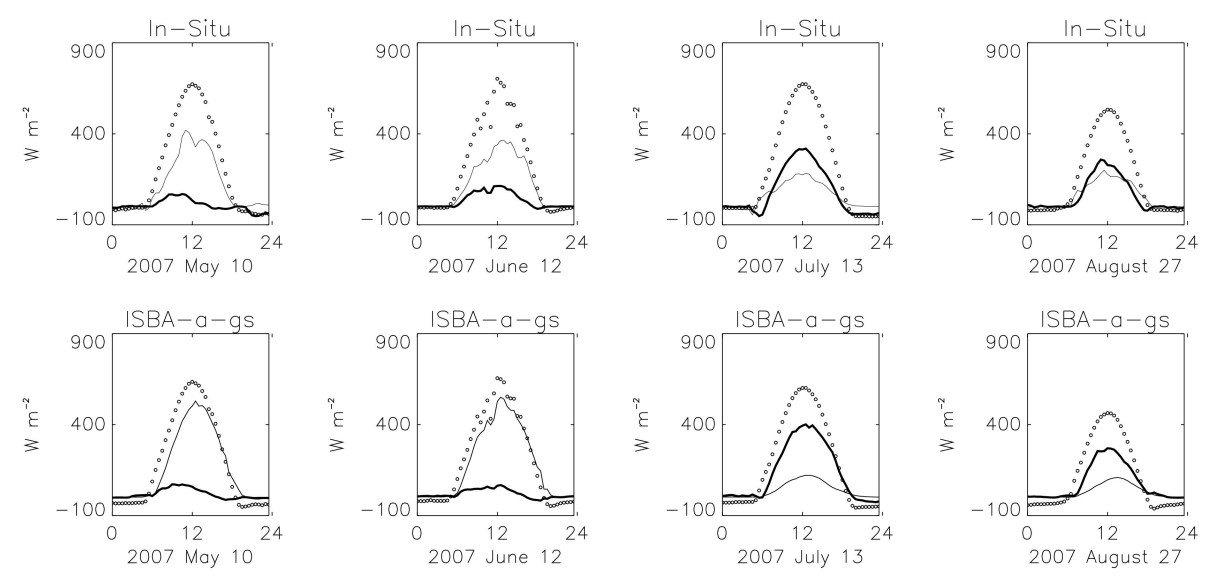

Fig. 5. Observed (top) and simulated (bottom) energy fluxes for 4 daily cycles in May, June, July and August 2007: Rn (dots), H (thick), LE (fine line).

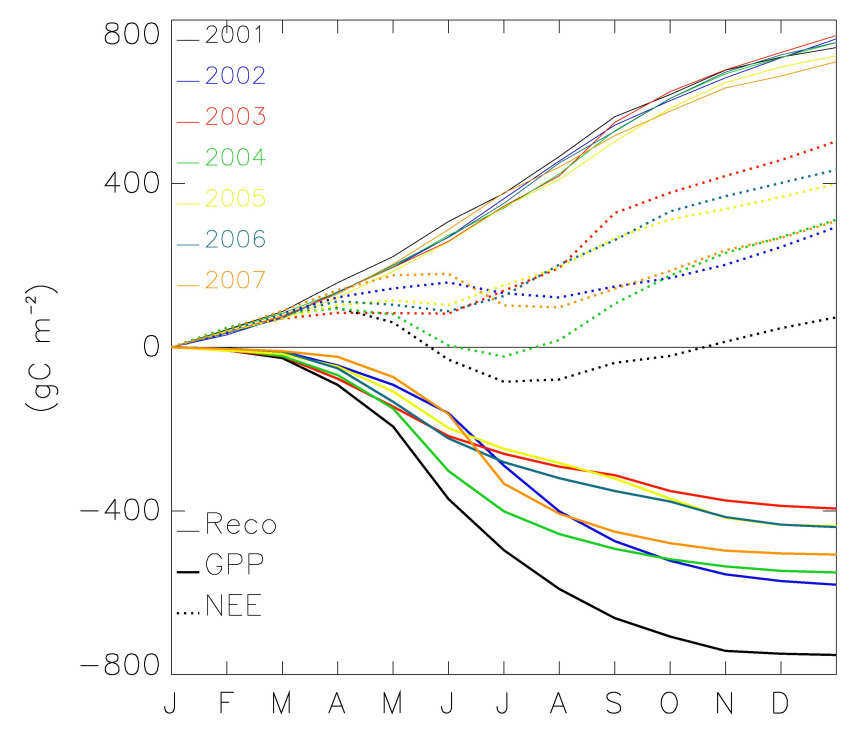

Fig. 6. Annual cumulative curves of $R_{\text {eco }}$ (thin line), GPP (thick line) and NEE (dashed line) for a seven year (2001-2007) period simulated by ISBA-A-gs, using Eq. (4) for $R_{\text {eco }}$.

amount is higher than the one derived from Eq. (1). While a near equilibrium between $R_{\text {eco }}$ and GPP is observed in 2001, GPP is systematically lower than $R_{\text {eco }}$ for the other years (Table 5). In southwestern France, the 2001 annual cycle presented relatively standard conditions in terms of climate, which may explain the near equilibrium between GPP and $R_{\text {eco. }}$ In 2002 , the summer was particularly wet and, after 2001,2002 is the year presenting the highest modelled GPP. The greatest difference between $R_{\text {eco }}$ and GPP occured in 2003. In 2003, the spring and summer periods were anomalously dry in southwestern France and a reduction of primary production was observed, as throughout western Europe (Ciais et al., 2005).
The observed and simulated surface soil moisture $w_{\mathrm{g}}$, root-zone soil moisture $w_{2}$ and LAI are presented in Fig. 7. A good agreement between observed and modelled $w_{2}$ values is found: $r^{2}=0.91$, bias $=-0.004 \mathrm{~m}^{3} \mathrm{~m}^{-3}$ and RMSE $=0.02 \mathrm{~m}^{3} \mathrm{~m}^{-3}$. Scores are lower for $w_{\mathrm{g}}, r^{2}=0.65$, bias $=-0.03 \mathrm{~m}^{3} \mathrm{~m}^{-3}$ and RMSE $=0.07 \mathrm{~m}^{3} \mathrm{~m}^{-3}$.

The LAI estimates derived from reflectance measurements concur better with the destructive observations than the modelled estimates: the comparison between observed and modelled LAI (bottom) presents relatively poor statistical scores $\left(r^{2}=0.36\right.$, bias $=0.26 \mathrm{~m}^{2} \mathrm{~m}^{-2}$ and RMSE $=0.91 \mathrm{~m}^{2} \mathrm{~m}^{-2}$ ), whereas the LAI estimated from reflectance measurements correlates better with observed data $\left(r^{2}=0.55\right.$, bias $=-0.31 \mathrm{~m}^{2} \mathrm{~m}^{-2}$ and $\left.\operatorname{RMSE}=0.88 \mathrm{~m}^{2} \mathrm{~m}^{-2}\right)$.

\section{Discussion}

\subsection{Impact of soil moisture on $\boldsymbol{R}_{\text {eco }}$}

Accounting for the effect of soil moisture into the simple $Q_{10}$ formulation for ecosystem respiration is required to represent the seasonality of $R_{\text {eco }}$. This is particularly important during periods of the year with high temperatures and a limitation of the heterotrophic respiration by drought. Figures 2 and 3 show the seasonal and daily impacts of the new formulation, respectively. In Fig. 2, as the spring and summer of 2005 and 2006 are marked by high temperatures and scarce precipitation, the SMOSREX grassland is a sink of carbon (negative values of NEE) in April-May only. In 2007, the carbon sink is more pronounced and occurs from May to July. With Eq. (1), the net uptake of carbon starts earlier than with Eq. (4). This is due to the lower $\operatorname{Re}_{25}$ values used in Eq. (1), inducing lower $R_{\text {eco }}$ values when soil moisture is close to field capacity. Equation (1) is temperature-dependent, only, and the simulated $R_{\text {eco }}$ values are higher during the warm seasons (spring, summer, autumn) and lower at wintertime. 

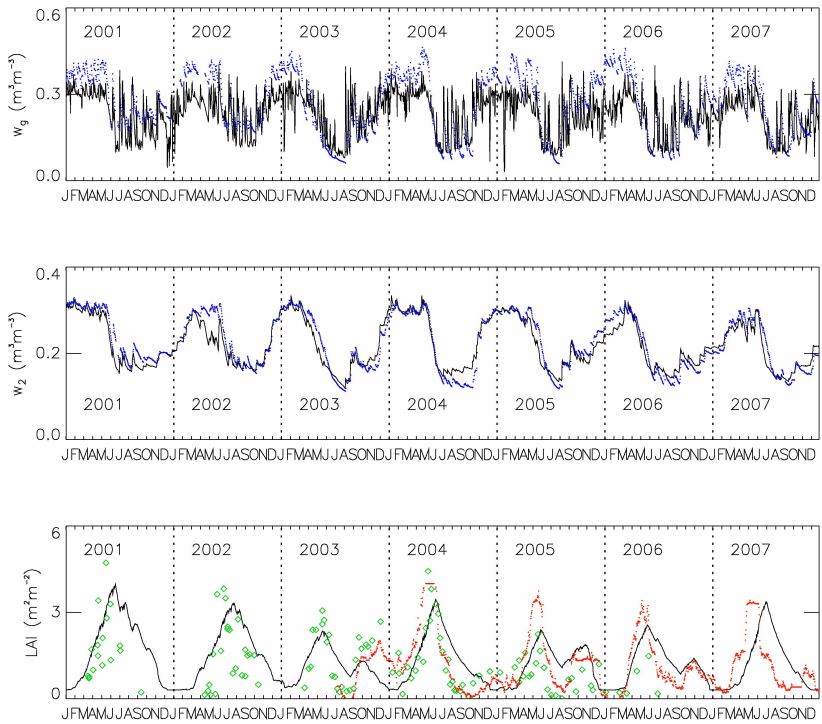

Fig. 7. Surface soil moisture $\left(w_{\mathrm{g}}\right)$, root-zone soil moisture $\left(w_{2}\right)$, and Leaf Area Index (LAI) of the SMOSREX grassland for a seven year (2001-2007) period, simulated by ISBA-A-gs (black solid lines) and observed (blue dots for soil moisture, green diamonds for LAI estimates derived from destructive measurements, red dots for LAI estimates derived from surface reflectance measurements).

The use of Eq. (4) produces lower $R_{\text {eco }}$ values during the dry periods as it is also controlled by soil moisture. At summertime, the observed soil temperature at $20 \mathrm{~cm}$ may reach relatively high values (up to $24^{\circ} \mathrm{C}$ ) and Eq. (1) gives high values of $R_{\text {eco. }}$. Nevertheless, during these periods, the low water content available for plant growth and for the decomposition of the soil's organic matter does not allow high values for $R_{\text {eco }}$, and this effect is accounted for by Eq. (4). In wet periods, where $w_{\mathrm{g}}$ is close to $w_{\mathrm{fc}}$, the $R_{\mathrm{eco}}$ values given by Eq. (1) or Eq. (4) are similar. Finally, Table 3 shows that the calibration of Eq. (4) derived from either the modelled $R_{\text {eco }}$ of ISBA-CC or from the observed nighttime observations, present similar statistical scores. The similarities between these scores shows that, for this grassland, ISBA-CC can be used to calibrate the ecosystem calibration of ISBA-A-gs.

Equation (4) assumes a linear positive effect of soil moisture on ecosystem respiration and no effect above the field capacity value, and does not consider the fact that above the field capacity, soil moisture may decrease soil respiration due to anaerobic conditions (Skopp et al., 1990). This effect is accounted for in the ISBA-CC model (Gibelin et al., 2008). In this study, the $f\left(w_{\mathrm{g}}\right)$ factor is applied to the ecosystem respiration, not to the soil respiration, which is not explicitly calculated by ISBA-A-gs. An attempt was made to apply more complex $f\left(w_{\mathrm{g}}\right) R_{\text {eco }}$ functions, including functions similar to the formulation used in ISBA-CC for soil respiration (Gibelin et al., 2008), without significantly impacting the statistical scores.

\subsection{GPP response to temperature}

Figure 4's result on the temperature dependence of the GPP is consistent with a previous study performed by Brut et al. (2009), who showed that the current version of ISBA-Ags tends to overestimate the optimal temperature for photosynthesis, in the case of mountainous grasslands of southwestern France. Those grasslands grow in cooler and wetter conditions than those observed at SMOSREX. The similar results found in this study for the SMOSREX plain grassland tend to show that this temperature issue might be common to $\mathrm{C} 3$ grasslands, irrespective of climate conditions. It must be noted that the temperature response shortcoming of the model may be due to the multispecific composition of a natural grassland. Indeed, the growing cycles of several herbaceous plants overlap, and the GPP temperature response may vary from one species to another.

\subsection{Leaf onset simulations}

Leaf onset differences are observed in Fig. 7, between the reflectance-derived and the modelled LAI: the growing period starts later in the simulations. Those results are consistent with the lower optimal temperature found with the observed GPP. The SMOSREX grassland starts growing at temperatures far below the optimal temperature used in ISBAA-gs, inducing this temporal gap between observed and modelled LAI. In order to quantify the contribution of the uncertainty of the simulated LAI on the simulated carbon fluxes, the model was run without the interactive LAI option, i.e. forced by the LAI observations. The LAI estimated from reflectance measurements was prescribed to the model. This modification led to slightly better NEE scores, as shown in Table 3 (see the results given for prescribed LAI). The $r^{2}$ increases from 0.63 to 0.66 , and the RMSE decreases from 3.87 to $3.48 \mu \mathrm{mol} \mathrm{m}{ }^{-2} \mathrm{~s}^{-1}$. The improvement of the simulated NEE (even if it is small) observed, when the model is forced with LAI observations, shows that the use of such data in a Land Data Assimilation Systems (Sabater et al., 2008; Rüdiger et al., 2010) might contribute to improve NEE simulations.

\subsection{Impact of uncertainties in the soil profile description}

The relatively high RMSE found for LE, and the large bias found for $\mathrm{H}$ (Table 4) may be due to the simplified description of the soil hydrology used in the model (2 layers), and to the lack of description of the litter, which is particularly thick at this site. A more detailed description of the different layers of the soil, and of the effect of the litter on the water and heat exchanges, might improve the simulations (GonzalezSosa et al., 2001). Figure 8 (left) shows the observed $w_{\mathrm{g}}$ as a function of the modelled $w_{\mathrm{g}}$ at a daily time step, for the 2005-2007 period. The modelled surface soil moisture $w_{\mathrm{g}}$ correlates satisfactorily with the observations $\left(r^{2}=0.65\right.$, 

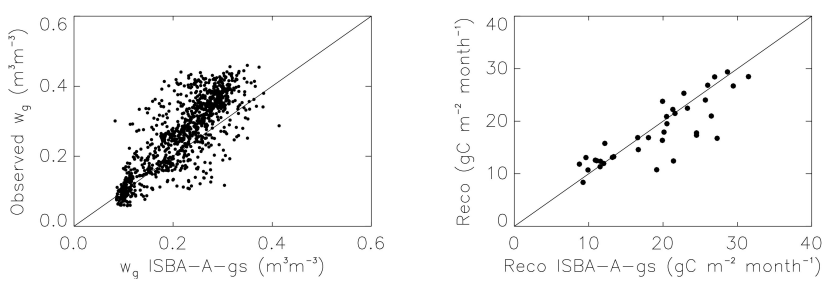

Fig. 8. Surface soil moisture and ecosystem respiration $\left(w_{\mathrm{g}}\right.$ and $R_{\text {eco }}$ ): observations vs. the ISBA-A-gs simulations for a 3-year period (2005-2007). For $w_{\mathrm{g}}$ (left) daily average values are considered. For $R_{\text {eco }}$ (right) monthly accumulated values are considered, based on Eq. (4) used in the ISBA-A-gs model or on Eq. (4) with observed $w_{\mathrm{g}}$ and soil temperature values.

bias $=-0.04 \mathrm{~m}^{3} \mathrm{~m}^{-3}$ and RMSE $=0.07 \mathrm{~m}^{3} \mathrm{~m}^{-3}$ ). However, the modelled $w_{\mathrm{g}}$ is too low in wet conditions. In the 2-layer version of the model used in this study, the $w_{\mathrm{g}}$ simulated by ISBA-A-gs corresponds to a skin soil surface layer, whereas the observed surface soil moisture at the SMOSREX site, with a vertically installed ThetaProbe, corresponds to a relatively thick soil layer of $6 \mathrm{~cm}$. This may explain the lower scores found for $w_{\mathrm{g}}$ and the high variability observed on Fig. 7 (top). The same wilting point and field capacity values (Table 1) are used for the two layers of the model, whereas in the real world, the soil properties close to the surface usually differ from those of deeper layers. However, scaling $w_{\mathrm{g}}$ to field capacity in Eq. (3) permits limiting the impact of this effect on $R_{\text {eco }}$. In order to assess the impact of this error on the simulated $R_{\text {eco }}$, Fig. 8 presents monthly $R_{\text {eco }}$ estimates calculated using Eq. (4) and the observed $w_{\mathrm{g}}$ and soil temperature (at $20 \mathrm{~cm}$ ), as a function of the $R_{\text {eco }}$ derived from the ISBA-A-gs simulations. It seems that the uncertainty on the range of daily $w_{\mathrm{g}}$ is not too detrimental to the monthly $R_{\text {eco }}$ simulations.

Finally, it must be noted that the thick litter layer, at the surface of the soil, may impact the heterotrophic component of $R_{\text {eco. }}$. This is why $w_{\mathrm{g}}$ is used in this study as a factor of $R_{\text {eco }}$ (Eq. 4), instead of the root-zone soil moisture $w_{2}$. An attempt to use $w_{2}$ in Eq. (4) produced lower scores for nighttime NEE. For other sites, it is likely that using $w_{2}$ would produce better results, but this needs further confirmation.

\section{Conclusions}

The implementation of a representation of the soil moisture effect in the ecosystem respiration formulation of ISBA-Ags increased the correlation between observed and modelled NEE for a temperate grassland (the SMOSREX experimental site). Eddy covariance $\mathrm{CO}_{2}$ flux measurements permitted the estimation of the ecosystem respiration parameter $\left(\operatorname{Re}_{25}\right)$. This study also underlines the necessity of measuring water deposition at the surface (caused by dew, or rain) as it has a significant impact on the quality of eddy correlation observations.

It is shown that the Carbon Cycle version of the ISBA land surface model, ISBA-CC, can be used to estimate the $\operatorname{Re}_{25}$ parameter used in the simplified $R_{\text {eco }}$ formulation of ISBAA-gs. Thus, $R_{\text {eco }}$ estimates from ISBA-CC could be used to generalize the simplified (and more tractable) $\mathrm{Re}_{25}$ parameterisation for other ecosystems and climates where $\mathrm{CO}_{2}$ flux measurements are not available.

At the SMOSREX site, GPP estimates can be derived from the observed NEE and from $R_{\text {eco }}$ values obtained from soil temperature and soil moisture observations. It is found that the optimal temperature used in the model for photosynthesis is too high. While the modelled GPP peaks at about $24^{\circ} \mathrm{C}$, the observed GPP presents a weaker response to temperature and the highest values occur below $20^{\circ} \mathrm{C}$. In the same way, the temporal shift between observed and modelled LAI tends to indicate that the optimal temperature used in SURFEX is too high. This is consistent with the analysis of ISBA-A-gs simulations for a mountainous grassland performed by Brut et al. (2009). Finally, a comparison between observed and modelled energy fluxes (Rn, LE and $\mathrm{H}$ ) leads to satisfactory correlations, despite a marked bias for $\mathrm{H}$. Two methods to estimate $\mathrm{H}$ were compared (eddy covariance and aerodynamic methods). The eddy covariance method correlates much better with model simulations than the aerodynamic method.

Acknowledgements. The work of C. Albergel was supported by Centre National d'Etudes Spatiales (CNES) and Météo-France. S. Lafont was supported by the GEOLAND2 project, co-funded by the European Commission within the GMES initiative in FP7. The SMOSREX project was co-funded by the "Programme National de Télédétection Spatiale" and by the "Programme Terre Océan Surface Continentales et Atmosphère" (CNES), and by participants of the experiment: CESBIO (CNES, CNRS, IRD, UPS), CNRM/GAME (Météo-France, CNRS), INRA and ONERA, all in the framework of the SMOS science preparatory program.

\section{Edited by: A. Neftel}

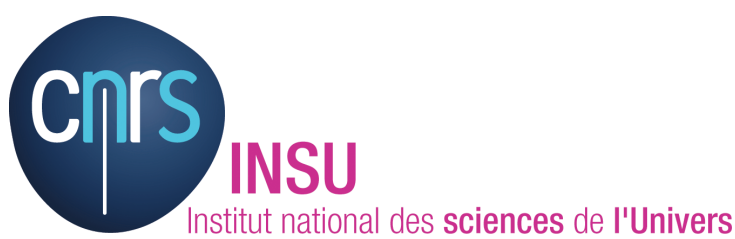

The publication of this article is financed by CNRS-INSU. 


\section{References}

Albergel, C., Calvet, J.-C., Mahfouf, J.-F., Rüdiger, C., Barbu, A. L., Lafont, S., Roujean, J.-L., Walker, J. P., Crapeau, M., and Wigneron, J.-P.: Monitoring of water and carbon fluxes using a land data assimilation system: a case study for southwestern France, Hydrol. Earth Syst. Sci. Discuss., 7, 1705-1744, doi:10.5194/hessd-7-1705-2010, 2010.

Aubinet, M., Grelle, A., Ibrom, A., Rannik, Ü., Moncrieff, J., Foken, T., et al.: Estimates of the annual net carbon and water exchange of forests: the EUROFLUX methodology, Adv. Ecol. Res., 30, 113-175, 2000.

Baldocchi, D., Falge, E., Gu, L., Olson, R., Hollinger, D., Running, S., Anthoni, P., Bernhofer, C., Davis, K., Evans, R., Fuentes, J., Goldstein, A., Katul, G., Law, B., Lee, X., Malhi, Y., Meyers, T., Munger, W., Oechel, W., Paw, K. T., Pilegaard, K., Schmid, H. P., Valentini, R., Verma, S., Vesala, T., Wilson, K., and Wofsy, S.: FLUXNET: a new tool to study the temporal and spatial variability of ecosystem-scale carbon dioxide, water vapour, and energy flux densities, B. Am. Meteorol. Soc., 82, 2415-2434, 2000.

Brut, A., Rüdiger, C., Lafont, S., Roujean, J.-L., Calvet, J.-C., Jarlan, L., Gibelin, A.-L., Albergel, C., Le Moigne, P., Soussana, J.-F., Klumpp, K., Guyon, D., Wigneron, J.-P., and Ceschia, E.: Modelling LAI at a regional scale with ISBA-A-gs: comparison with satellite-derived LAI over southwestern France, Biogeosciences, 6, 1389-1404, doi:10.5194/bg-6-1389-2009, 2009.

Calvet, J.-C., Noilhan, J., Roujean, J.-L., Bessemoulin, P., Cabelguenne, M., Olioso, A., and Wigneron, J.-P.: An interactive vegetation SVAT model tested against data from six contrasting sites, Agr. Forest Meteorol., 92, 73-95, 1998.

Calvet, J.-C., Bessemoulin, P., Noilhan, J., Berne, C., Braud, I., Courault, D., Fritz, N., Gonzalez-Sosa, E., Goutorbe, J.-P., Haverkamp, R., Jaubert, G., Kergoat, L., Lachaud, G., Laurent, J.-P., Mordelet, P., Olioso, A., Péris, P., Roujean, J.-L., Thony, J.-L., Tosca, C., Vauclin, M., and Vignes, D.: MUREX: a land-surface field experiment to study the annual cycle of the energy and water budgets, Ann. Geophys., 17, 838-854, doi:10.5194/angeo-17-838-1999, 1999.

Calvet, J.-C.: Investigating soil and atmospheric plant water stress using physiological and micrometeorological data, Agr. Forest Meteorol., 103, 229-247, 2000.

Calvet, J.-C. and Soussana, J.-F.: Modelling $\mathrm{CO}_{2}$-enrichment effects using an interactive vegetation SVAT scheme, Agr. Forest Meteorol., 108, 129-152, 2001.

Ciais, P., Viovy, N., Reichtein, M., Og'ee, J., Granier, A., Knohl, A., Rambal, S., Sanz, M.-J., Schulze, D., Chevallier, F., and Valentini, R.: An unprecedented reduction in primary productivity of Europe during the summer heatwave in 2003, Nature, 437, 529533, doi:10.1038/nature.03972, 2005.

De Rosnay, P., Calvet, J.-C., Kerr, Y., Wigneron, J.-P., Lemaître, F., et al.: SMOSREX: A long term field campaign experiment for soil moisture and land surface processes remote sensing, Remote Sens. Environ., 102, 377-389, 2006.

Deardorff, J. W.: Efficient prediction of ground surface temperature and moisture with inclusion of a layer of vegetation, J. Geophys. Res., 83(C4), 1889-1903, 1978.

Epron, D., Farque, L., Lucot, E., and Badot, P.-M.: Soil $\mathrm{CO}_{2}$ efflux in a beech forest: dependence on soil temperature and soil-water content, Ann. For. Sci., 56, 221-226, 1999.
Foken, T.: Measurement of meteorological elements, in: Micrometeorology, Springer-Verlag, 188-217, 2008.

Gibelin, A.-L., Calvet, J.-C., Roujean, J.-L., Jarlan, L., and Los, S. O.: Ability of the land surface model ISBA-A-gs to simulate leaf area index at global scale: Comparison with satellites products, J. Geophys. Res., 111, D18102, doi:10.1029/2005JD006691, 2006.

Gibelin, A.-L., Calvet, J.-C., and Viovy, N.: Modelling energy and $\mathrm{CO}_{2}$ fluxes with an interactive vegetation land surface model evaluation at high and middle latitudes, Agr. Forest Meteorol., 148, 1611-1628, 2008.

Gonzalez-Sosa, E., Braud, I., Thony, J.-L., Vauclin, M., and Calvet, J.-C.: Heat and waterexchanges of fallow land covered with plant-residue mulch layer: a modeling study using the three year MUREX dataset, J. Hydrol., 244, 119-136, 2001.

Goulden, M. L., Munger, J. W., Fan, S. M., Daube, B. C., and Wofsy, S. C.: Measurements of carbon sequestration by long term eddy covariance: methods and a critical evaluation of accuracy, Global Change Biol., 2, 169-182, 1996.

Heusinkveld, B. G., Jacobs, A. F. G., and Holtslag, A. A. M.: Effect of open-path gas analyser wetness on eddy covariance flux measurements: a proposed solution, Agr. Forest Meteorol., 148, 1563-1573, 2008.

Holt, J. A., Hodgen, J., and Lamb, D.: Soil respiration in the seasonally dry tropics near Tawnsville, North Queensland, Soil Biol. Biochem., 28, 737-745, 1990.

Janssens, I. A., Lankreijer, H., Matteucci, G., Kowalski, A. S., Buchmann, N., et al.: Productivity overshadows temperature in determining soil and ecosystem respiration across European forests, Global Change Biol., 7(3), 269-278, 2001.

Joffre, R., Rambal, S., and Romane, F.: Local variations of ecosystem function in Mediterranean evergreen oak woodland, Ann. For. Sci., 53, 561-570, 1996.

Katterer, T., Reichtein, M., Andr'en, O., and Lomander, A.: Temperature dependence of organic matter decomposition: a critical review using literature data analysed with different models, Biol. Fert. Soils, 27, 258-262, 1998.

Kicklighter, D. W., Melillo, J. M., Peterjohn, W. T., Rastetter, E. B., McGuire, D. A., Steudler, P. A., and Aber, J. D.: Aspects of spatial and temporal aggregation in estimating regional carbon dioxide fluxes from temperate forest soil, J. Geophys. Res., 99, 1305-1315, 1994.

Kirschbaum, M. U. F.: The temperature dependence of soil organic matter decomposition, and the effect of global warming on soil organic C storage, Soil Biol. Biochem., 27, 753-760, 1995.

Le Moigne, P.: SURFEX scientific documentation, Note de centre du Groupe de Météorologie à Moyenne Echelle, 87, MétéoFrance, online available at: http://www.cnrm.meteo.fr/surfex/, last access: January 2010), CNRM, Toulouse, France, 211 pp., 2009.

Lloyd, J. and Taylor, J. A.: On the temperature dependence of soil respiration, Funct. Ecol., 8, 315-323, 1994.

Martin, E., Le Moigne, P., Masson, V., Boone, A., Bogatchev, A., et al.: Le code de surface externalisé SurfEx de Météo-France, Atelier de modélisation de l'atmosphère, 16-18 January 2007, Toulouse, 2007.

Mahfouf, J.-F. and Noilhan, J.: Inclusion of gravitational drainage in a land surface scheme based on the force-restored method, J. Appl. Meteorol., 35, 987-992, 1996. 
Moncrieff, J., Valentini, R., Greco, S., Seufert, G., and Ciccioli, P.: Trace gas exchange over terrestrial ecosystems: method and perspectives in micrometeorology, J. Exp. Bot., 48, 1133-1142, 1997.

Noilhan, J. and Planton, S.: A simple parameterisation of land surface processes for meteorological model, Mon. Weather Rev., 117, 356-549, 1989.

Noilhan, J. and Mahfouf, J.-F.: The ISBA land surface parameterisation scheme, Global Planet. Change, 13, 145-149, 1996.

Parton, W. J., Schimel, D. S., Cole, C. V., and Ojima, D. S.: Analysis of factors controlling soil organic matter levels in Great Plains grasslands, Soil Sci. Soc. Am. J., 51, 1173-1179, 1987.

Raich, J. W., Potter, C. S., and Bhagawati, D.: Interannual variability in global soil respiration, Global Change Biol., 8, 800-812, 2002.

Rivalland, V., Calvet, J.-Ch., Berbigier, P., Brunet, Y., and Granier, A.: Transpiration and $\mathrm{CO}_{2}$ fluxes of a pine forest: modelling the undergrowth effect, Ann. Geophys., 23, 291-304, doi:10.5194/angeo-23-291-2005, 2005.
Roujean, J.-L. and Lacaze, R.: Global mapping of vegetation parameters from POLDER multiangular measurements for studies of surface-atmosphere interactions: A pragmatic method and its validation, J. Geophys. Res., 107(D12), 4150, doi:10.1029/2001JD000751, 2002.

Rüdiger, C., Albergel, C., Mahfouf, J.-F., Calvet, J.-C., and Walker, J. P.: Evaluation of Jacobians for Leaf Area Index data dssimilation with an Extended Kalman Filter, J. Geophys. Res., 115, D09111, doi:10.1029/2009JD012912, 2010.

Sabater, J. M., Rüdiger, C., Calvet, J.-C., Fritz, N., Jarlan, L., and Kerr, Y.: Joint assimilation of surface soil moisture and LAI observations into land surface model, Agr. Forest Meteorol., 148, 1362-1373, doi:10.1016/j.agrformet.2008.04.003, 2008.

Schlesinger, W. H. and Andrews, J. A.: Soil respiration and the global carbon cycle, Biogeochemistry, 48, 7-20, 2000.

Singh, J. S. and Gupta, S. R.: Plant decomposition and soil respiration in terrestrial ecosystem, Bot. Rev., 43, 449-528, 1977.

Skopp, J., Jawson, M. D., and Doran, J. W.: Steady-state aerobic microbial activity as a function of soil water content, Soil Sci. Soc. Am. J., 54, 1619-1625, 1990. 